\title{
Heat-shock protein 70 gene sequencing for Leishmania species typing in European tropical infectious disease clinics
}

G Van der Auwera (gvdauwera@itg.be) ${ }^{1}$, I Maes ${ }^{1}$, S De Doncker ${ }^{1}$, C Ravel $^{2}$, L Cnops 3 , M Van Esbroeck ${ }^{3}$, A Van Gompel $^{3}$, J Clerinx³, J C Dujardin ${ }^{1,4}$

1. Department of Biomedical Sciences, Institute of Tropical Medicine, Antwerp, Belgium

2. Centre National de Référence des Leishmania, University of Montpellier, Montpellier, France

3. Department of Clinical Sciences, Institute of Tropical Medicine, Antwerp, Belgium

4. Department of Biomedical Sciences, University of Antwerp, Antwerp, Belgium

We describe Leishmania species determination on clinical samples on the basis of partial sequencing of the heat-shock protein 70 gene ( $h s p 70$ ), without the need for parasite isolation. The method is especially suited for use in non-endemic infectious disease clinics dealing with relatively few cases on an annual basis, for which no fast high throughput diagnostic tests are needed. We show that the results obtained from this gene are in nearly perfect agreement with those from multilocus enzyme electrophoresis, which is still considered by many clinicians and the World Health Organization (WHO) as the gold standard in Leishmania species typing. Currently, 203 sequences are available that cover the entire $h s p 70$ gene region analysed here, originating from a total of 41 leishmaniasis endemic countries, and representing 15 species and sub-species causing human disease. We also provide a detailed laboratory protocol that includes a step-by-step procedure of the typing methodology, to facilitate implementation in diagnostic laboratories.

\section{Introduction}

As a result of current human mobility, European infectious disease clinics are occasionally confronted with leishmaniasis patients who got infected in an area endemic for Leishmania outside their own country. Typically it concerns tourists, expatriates, military staff, migrants, and relatives visiting friends or family. In many of these centres, the number of such cases seen annually is limited, and investing in the validation of high-throughput methods for discriminating the medically relevant species is therefore too costly. Nevertheless, especially in the case of tegumentary leishmaniasis, knowledge of the aetiological agent is highly relevant, as the disease prognosis and treatment choice depend on it [1-8]. However, one cannot always rely on the known epidemiology in the suspected region of infection. Firstly, because such information is often inaccurate or outdated, and secondly, because the geographic area where the patient got infected may not be known exactly if they resided in different endemic areas or countries. Moreover, even if the exact location of infection and epidemiology are known, different species may circulate sympatrically in a given region. Hence, there is a need for easily applicable, straightforward and standardised species discrimination methods that must above all be accurate, rather than allowing to handle many samples in a highthroughput fashion.

Over the past few years, we have been investing in the use of the heat-shock protein 70 gene ( $h s p 70$ ) for discrimination of medically important Leishmania species worldwide [9-12]. Initially developed for species discrimination in the New World subgenus L. (Viannia) by restriction fragment length polymorphism (RFLP) analysis [13], we have upgraded the specificity and sensitivity of the hsp7o PCR amplification strategy to suit all Leishmania species [12]. In this paper we report on the power of Leishmania species typing on the basis of $h s p 70$ sequences rather than RFLP. The approach is directed specifically towards diagnosis in clinical laboratories dealing with relatively few cases on an annual basis, such as our Institute of Tropical Medicine in Antwerp where an average of 15 patients are diagnosed each year. The method described here was developed in the framework of a European consortium of tropical infectious disease clinics called 'LeishMan' (www. leishman.eu), embedded in the European network for tropical medicine and travel health TropNet (www.tropnet.net). LeishMan aims at characterising Leishmania parasites using a standardised molecular assay that can be applied for clinical samples, without the need for parasite culture.

Several other single-locus assays have been used for sequence-based species discrimination, such as the mini-exon, the $7 \mathrm{SL}-\mathrm{RNA}$, and the ribosomal DNA-ITS1 
Position of PCR primers and products used for sequencing on the hsp70 coding region of Leishmania major strain MHOM/IL/81/Friedlin

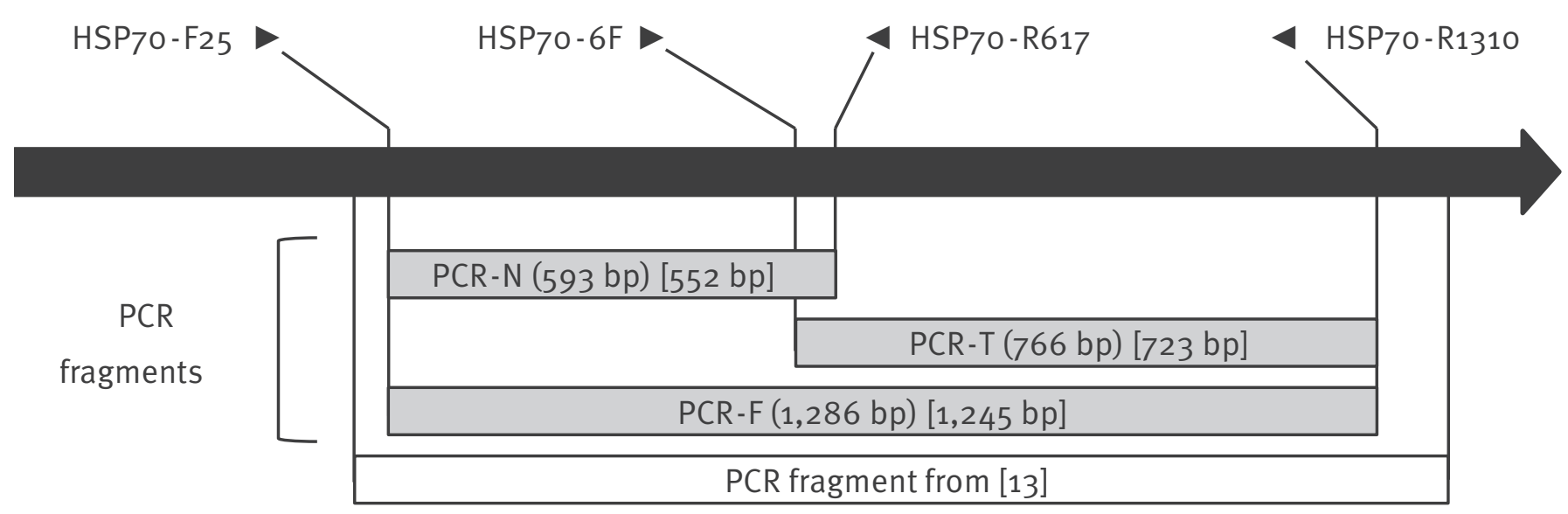

GenBank accession number FR796424.

The size of the PCR products is indicated between round brackets. The size of the sequenced fragments between the PCR primers is indicated between square brackets.

Black arrow in ' ${ }^{\prime}$ to 3 ' direction. primer extending in the sense direction of the gene; 4 primer extending in the antisense direction of the gene. The region in the white box is the PCR fragment reported in [13].

[14-17]. We found that hsp7o has some advantages over these (data not shown): it is easily comparable across all Leishmania species worldwide as there is no size variation in the gene [9], it discriminates all relevant species in both subgenera L. (Leishmania) and L. (Viannia), and PCRs have been optimised for direct amplification from clinical samples $[10,12]$. The gene is arranged as a tandem repeat unit, with almost no sequence variation between the coding sequences of the different copies $[18,19]$. In this paper we assess the concordance of Leishmania species typing with hsp7o sequences on the one hand, and results obtained from other genetic targets and multilocus enzyme electrophoresis (MLEE) on the other hand.

\section{Methods}

\section{Hsp70 amplification and sequencing}

Leishmania hsp7o sequences from 64 cultures and 36 rDNA-PCR-confirmed $[20,21]$ clinical samples were determined on the basis of a single PCR amplicon, i.e. PCR-F in Figure 1. Ca. 50 of these cultures were obtained from the Centre National de Référence des Leishmania (Montpellier, France). Among the clinical samples, 27 were from cutaneous lesions (mostly biopsies), one from a mucocutaneous lesion, two from visceral leishmaniasis patients, and six from an unknown clinical background. In the rare occasions where direct amplification of PCR-F failed from the clinical sample DNA extract, or when an insufficient amount of amplicon was obtained for sequencing, two shorter PCRs were used that together cover the same fragment: PCR-N and PCR-T (Figure 1). These can be run directly on the sample DNA, or alternatively as heminested PCRs using the PCR-F amplicon as first round PCR. A detailed protocol is available from www.itg.be/ LeishmaniaHSP7o.

All PCRs were performed in $25 \mu \mathrm{l} 1 \mathrm{x}$ standard PCR buffer (Qiagen, Hilden, Germany), supplemented by $1 \mathrm{mM} \mathrm{MgCl}{ }^{2}$ and $1 \times$ Qiagen Q-solution. Each reaction used $200 \mu \mathrm{M}$ of each dNTP, $0.8 \mu \mathrm{M}$ of each PCR primer (Table), and $1 \mathrm{U}$ of HotStarTaq Plus DNA polymerase (Qiagen). Up to $2.5 \mu \mathrm{l}$ of template were used. Cycling conditions were as follows: $5 \mathrm{~min}$ at $95{ }^{\circ} \mathrm{C}$ denaturation; 35 cycles of $40 \mathrm{sec}$ at $94^{\circ} \mathrm{C}, 1 \mathrm{~min}$ at $61^{\circ} \mathrm{C}, 2 \mathrm{~min}$ at $72{ }^{\circ} \mathrm{C}$; and finally $10 \mathrm{~min}$ at $72{ }^{\circ} \mathrm{C}$. For PCR-N and PCR$\mathrm{T}$, the elongation step was shortened to $1 \mathrm{~min}$ at $72{ }^{\circ} \mathrm{C}$.

PCR products were analysed on a $2 \%$ agarose gel to check for sufficient and specific amplification, based on the expected product sizes outlined in Figure 1. The fragments were sequenced with primers internal in the PCR fragment (see protocol on www.itg.be/ LeishmaniaHSP70). In some strains, a second nucleotide was detected below the main trace signal at some sequence positions. In such cases, IUPAC ambiguity codes [22] were introduced in the sequence whenever the secondary nucleotide showed at least $20 \%$ of the intensity of the main peak in each sequence read covering the respective position. The sequences from reference strains were submitted to the European Nucleotide Archive (www.ebi.ac.uk/ena).

Sequence analysis and typing

For the analysis presented in this paper, we compiled 


\begin{tabular}{|l|c|c|c|c|c|c|}
\hline Primer name & PCR & Sequence (5'-3') & Length & Orientation & $\begin{array}{c}\text { Annealing start } \\
\text { (5' of primer) }\end{array}$ & $\begin{array}{c}\text { Annealing end } \\
\text { (3' of primer) }^{\mathrm{a}}\end{array}$ \\
\hline HSP70-F25 & PCR-F/N & GGACGCCGGCACGATTKCT & 19 & Sense & 480 & 498 \\
\hline HSP70-6F & PCR-T & GTGCACGACGTGGTGCTGGTG & 21 & Sense & 1,000 & 1,020 \\
\hline HSP70-R617 & PCR-N & CGAAGAAGTCCGATACGAGGGA & 22 & Antisense & 1,072 & 1,051 \\
\hline HSP70-R1310 & PCR-F/T & CCTGGTTGTTGTTCAGCCACTC & 22 & Antisense & 1,765 & 1,744 \\
\hline
\end{tabular}

${ }^{a}$ Annealing position in GenBank entry FR796424 (hsp7o of L. major Friedlin strain).

Primers are listed in order of annealing in the coding sequence of the gene, from 5'-3' terminus.

107 available sequences covering the $1,245 \mathrm{bp}$ hsp70 PCR-F fragment (Figure 1) from GenBank (www. ncbi.nlm.nih.gov/genbank, accessed on 25 June 2013). These were aligned with the 100 sequences determined in this study. From the total of 207 sequences, 84 were typed by MLEE, and 54 on the basis of genes other than hsp7o. Many MLEE-typed isolates were analysed with genetic methods as well. For 12 sequences, we relied on the species identification as listed in GenBank, where the typing method is not specified. Finally, no typing data were available for the remaining 57 sequences, which included those determined for diagnosis. For the sequences described in the paper by Zhang et al. [23], we did not rely on the GenBank identification, as this was in conflict with data in the paper itself. Aligning was done manually, which was straightforward as no size variation was detected in 205 sequences, while two sequences showed a deletion of three nucleotides, corresponding to one amino acid.

Species delineation was based upon the clustering of aligned sequences in a comparative dendrogram, which was constructed with the freely available software package MEGA5 [24]. Dendrograms were built from the variable sites in the alignment using the neighbour-joining method, with pairwise gap deletion and 2,000 bootstrap replicates. As our aim was to find the most discriminative analysis method rather than to study evolution, we based our dendrograms on $p$ distances, and not on other models such as the popular Kimura 2-parameter method for calculating corrected distances. More details are available from the protocol on www.itg.be/LeishmaniaHSP70.

\section{Results}

The final alignment contained 207 sequences from 42 Leishmania-endemic countries, representing 18 species of which 15 are causing human disease (Figure 2 and supplementary dendrogram available at www. itg.be/LeishmaniaHSP70). As further detailed in the Discussion, four GenBank entries contained sequences that did not correspond to the indicated isolate, reducing the number of trustworthy sequences to 203 from 41 countries.

The clustering of a representative selection of the hsp7o sequences is depicted in Figure 3. A dendrogram of the complete set of available hsp7o sequences can be found at www.itg.be/LeishmaniaHSP70. The medically relevant clusters indicated in bold in these figures could be easily discriminated, and were supported by bootstrap values between 89 and $99 \%$ (Figure 3). These generally coincided with recognised species complexes. Within these complexes, a further distinction was possible, as indicated by the dotted lines. These subdivisions had a lower bootstrap support, between 53 and 71\% (Figure 3).

Almost all hsp7o clusters showed a perfect agreement with MLEE-based classifications (isolates identified with ' $M$. species') and typing results from genetic loci different from hsp7o (identified with 'G. species'). There were nevertheless a few exceptions, which are indicated with * and ** following the taxon designation. Of the 81 isolates typed on the basis of MLEE and from which a trustworthy $h s p 70$ sequence was reported, 76 (94\%) grouped in the respective hsp7o cluster. Of the 54 isolates typed on the basis of non-hsp7o genetic loci, 50 (93\%) grouped in the respective hsp7o cluster. A few isolates did not group with any known species clade, notably IMON/CN/90/KXG-Y, MHOM/--/94/ CRE58, MHOM/PE/--/CU00181, MHOM/PE/95/LQ-8, and MCAN/IR/96/LON-49.

The $L$. braziliensis isolates separated into two clearly distinct clusters, named $L$. braziliensis outlier and $L$. braziliensis complex, which also contained L. peruviana. Even though these two clusters are sister taxa, the bootstrap support was weak (53\%). In some dendrograms, the two clusters did not form sister clades, and the outliers rather grouped with $L$. naiffi (results not shown). One strain, MHOM/PE/--/CUoo181, was intermediate between both $L$. braziliensis clusters. 


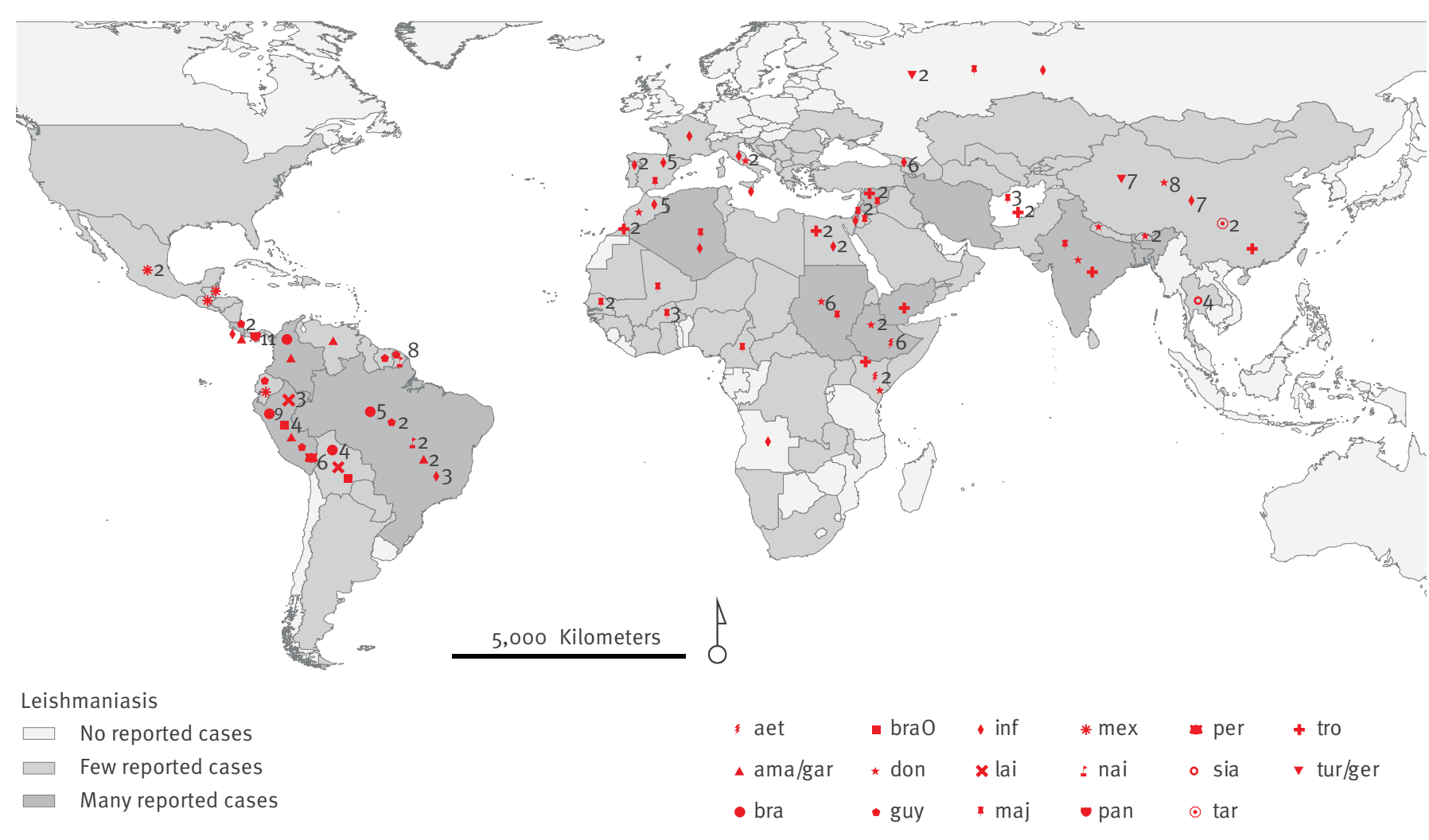

Of 203 trustworthy sequences, this figure includes the 190 with known origin of infection and species.

The shaded areas are considered endemic for Leishmania, the darkly shaded areas carry the heaviest burden of visceral and/or cutaneous leishmaniasis according to [46]. Strains are assigned at country level, the position of the symbols within a country has no meaning. The former Soviet Union is considered as one country; Costa Rica and Panama are joined because of their small size. If one symbol represents several strains, the number is given on the right, otherwise it represents only one strain.

Species: aet: L. aethiopica; ama: L. amazonensis; arc: L. archibaldi; bra: L. braziliensis; braO: L. braziliensis outlier; bra-braO: hybrid; cha: L. chagasi; don: L. donovani; gar: L. garnhami; ger: L. gerbilli; guy: L. guyanensis; inf: L. infantum; lai: L. lainsoni; maj: L. major; mex:

L. mexicana; nai: L. naiffi; pan: L. panamensis; per: L. peruviana; sia: L. siamensis; tar: L. tarentolae; tro: L. tropica; tur: L. turanica.

Using the here presented hsp7o clustering system, we have so far been able to determine the infecting species in 33 clinical samples presented for diagnosis in our institute, and three from military personnel on mission in Afghanistan. These were from 14 different countries and represented eight Leishmania species (Figure 3 and supplementary dendrogram). The majority $(n=27)$ were from cutaneous lesions (mostly biopsies), one from a mucocutaneous lesion, and two from visceral leishmaniasis patients. From six samples the clinical presentation was not known.

\section{Discussion}

In general there is good agreement between typing results on the basis of $h s p 70$ and those based on other genes and MLEE, with the following exceptions: (i) L. chagasi isolates could not be distinguished from L. infantum, which agrees with previous studies showing that both are in fact one species, whereby L. chagasi is synonym of South-American L. infantum [25]. (ii) L. archibaldi grouped with L. donovani, in line with the current notion that it is not a separate species [26]. (iii) Two L. infantum isolates, MHOM/CN/94/ KXG-LIU and MHOM/CN/93/KXG-XU, were found clustering with $L$. donovani. According to the authors who published these sequences, however, the species identification is disputable and depends on the technique applied [23]. (iv) The MLEE identified L. donovani isolate MHOM/SU/84/MARZ-KRIM clustered with $L$. infantum. On the basis of at least eight other genes, this strain was indeed identified as $L$. infantum (data not shown). (v) Two L. guyanensis strains, MHOM/CO/83/ REST417 and MHOM/EC/90/Ul.031 were found in the L. panamensis cluster. Although it has been argued that L. panamensis is merely a geographically confined subcluster of $L$. guyanensis rather than a distinct species [9,27-29], both strains merit a more profound genetic analysis to evaluate their hsp7o classification. (vi) The L. braziliensis isolate MHOM/PE/2001/LH2140 clustered with $L$. peruviana, even though its sequence is different from those of the other L. peruviana strains. A genome-wide amplified fragment length polymorphism 


\section{FIGURE 3}

Dendrogram of selected Leishmania hsp70 sequences analysed in this study, including for each indicated cluster the most divergent sequences $(n=91)$
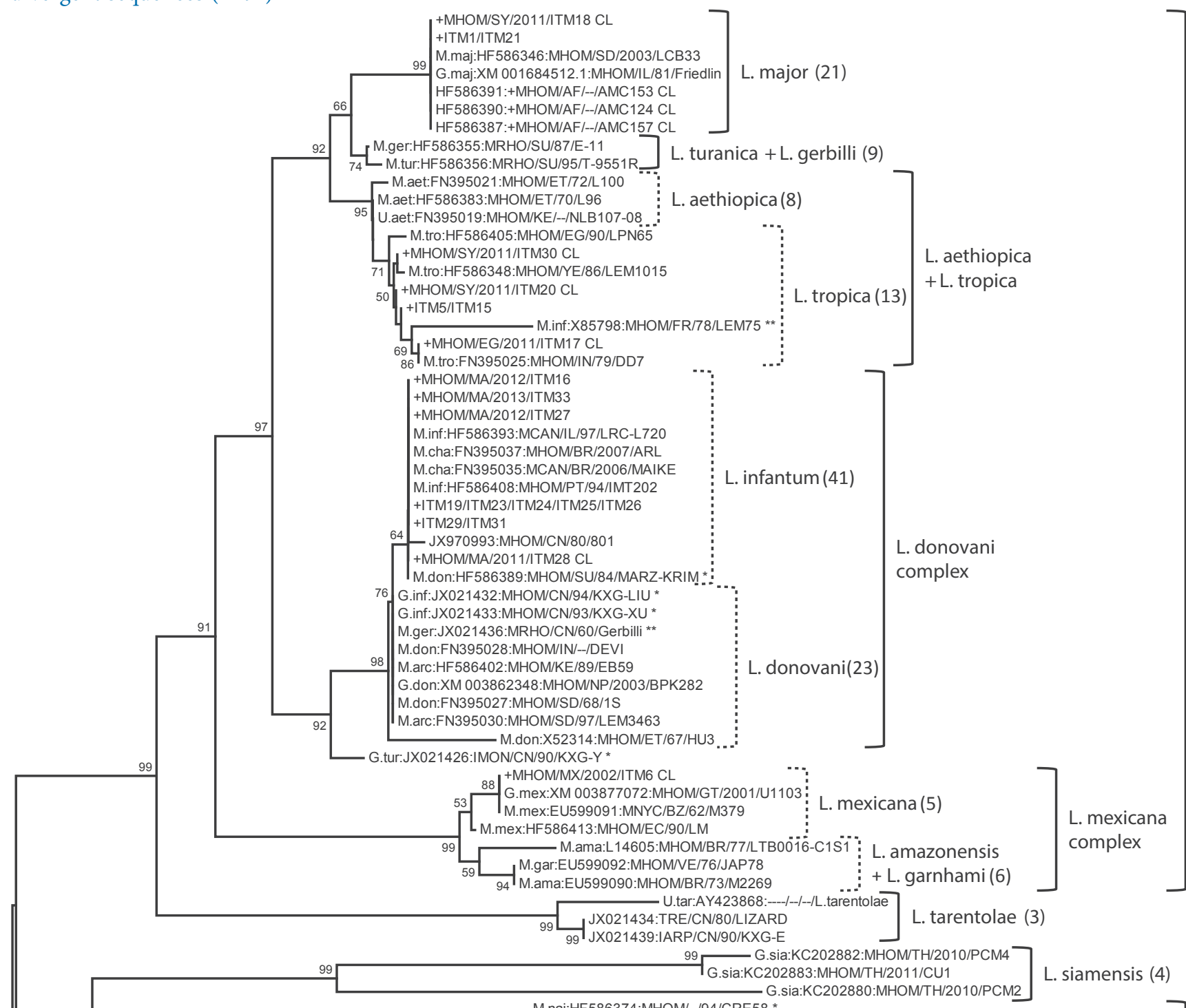

65 M.pan:EU599094:MHOM/PA/71/LS94

M.guy:HF586378:MHOM/EC/90/Ul.031 *

6 M.guy.HF586378:MHOM/EC/90/U1.031

66 M.pan:HF586359:MHOM/CR/2004/TIM13

61 M.guy:HF586357:MHOM/CO/83/REST417 *..

+ITM13/ITM14

94 M.guy:HF586360:MHOM/EC/90/JUBERLY

G.guy:FN395051:MHOM/PE/2002/LH2372

71 M.guy:HF586362:MHOM/GF/79/LEM85

+ MHOM/GF/2013/ITM32 CL

+ITM2/ITM3/ITM4/ITM7

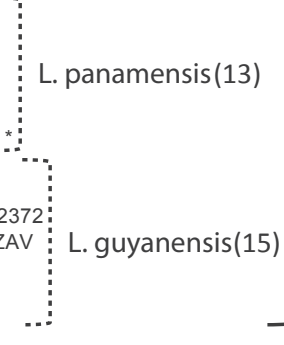


Dendrogram of selected Leishmania hsp70 sequences analysed in this study, including for each indicated cluster the most divergent sequences $(n=91)$

Each taxon is identified as follows:

(i) Identification method if available: G: genetic analysis other than hsp7o; M: multilocus enzyme electrophoresis; U: unknown typing method.

(ii) Species based on this identification method: aet: L. aethiopica; ama: L. amazonensis; arc: L. archibaldi; bra: L. braziliensis; bra0: L. braziliensis outlier; bra-bra0: hybrid; cha: L. chagasi; don: L. donovani; gar: L. garnhami; ger: L. gerbilli; guy: L. guyanensis; inf: L. infantum; lai: L. lainsoni; maj: L. major; mex: L. mexicana; nai: L. naiffi; pan: L. panamensis; per: L. peruviana; sia: L. siamensis; tar: L. tarentolae; tro: L. tropica; tur: L. turanica.

(iii) EBI/GenBank accession number if available.

(iv) World Health Organization (WHO) code: Missing data are indicated by

(v) Clinical samples diagnosed in this study are indicated with + in front of the taxon name, and those from the Institute of Tropical Medicine Antwerp are identified by ITM without WHO code, whereby identical sequences are presented as one taxon. CL following the WHO code indicates that the sample was taken from a cutaneous lesion.

(vi) Strains indicated with * cluster differently compared with other methods, those indicated with ** do not represent the strain as reported in GenBank.

The dissimilarity scale is presented at the bottom. Bootstrap values higher than $50 \%$ from a 2,000 replicate analysis are shown in percentages at the internodes. Clusters strongly supported are indicated in bold, those less supported are indicated by dotted lines. For each recognised cluster, the number of strains in the total of 207 available sequences is given between brackets.

(AFLP) analysis clearly identified this strain as L. braziliensis [19]. (vii) The MLEE-typed L. braziliensis isolate MCAN/PE/91/LEM2222 clustered with the L. braziliensis outliers, confirming results from several other genes (data not shown). This is in line with the fact that MLEE does not separate both $L$. braziliensis groups. (viii) L. braziliensis isolate MHOM/PE/--/CUo0181 clustered intermediate between $L$. braziliensis and $L$. braziliensis outliers, which agrees with AFLP data [19]. (ix) Two sequences were found in an incorrect species cluster: $\mathrm{MRHO} / \mathrm{CN} / 60 /$ Gerbilli and MHOM/FR/78/LEM75. According to GenBank data, JX021436 is the sequence from the WHO L. gerbilli reference strain MRHO/CN/6o/ Gerbilli, but it clustered among $L$. donovani, apart from the other $L$. gerbilli sequences. As the strain was not included in the publication describing related GenBank entries [23], there are no independent data to confirm the identity of the sequence. Moreover, several species designations in this set of GenBank entries (especially those listed as $L$. donovani) do not match those in the corresponding paper. MHOM/FR/78/LEM75 is a type strain of $L$. infantum, but it strongly grouped with $L$. tropica. Given that all 17 other $L$. infantum strains clustered correctly with $h s p 70$, it is reasonable to assume that the sequence in GenBank is erroneous. (x) Finally, four isolates, MHOM/PE/95/LQ-8, MCAN/IR/96/LON49, MHOM/--/94/CRE58, and IMON/CN/90/KXG-Y, did not group with any of the designated species complexes, the reason for which is unclear. The sequences reported for MHOM/PE/95/LQ-8 and MCAN/IR/96/LON49 were found related to the Leptomonas sp. sequence described in [30], and hence these do not match with the Leishmania isolates listed in GenBank (results not shown). MHOM/--/94/CRE58 and IMON/CN/90/KXG-Y were typed as $L$. naiffi and $L$. turanica, respectively, using several genes, and it is unclear why they did not group with their respective species.
Taken all evidence together, of the 135 trustworthy sequences for which either MLEE or independent genetic species identification was done, 130 (96.3\%) grouped with the correct species in the hsp7o sequence dendrogram; two (1.5\%) did not group with any species; and three $(2.2 \%)$ were assigned to the correct species complex, but the wrong species. Since we started routine species typing on the basis of hsp7o sequences, we could type 33 clinical samples that were sent to our clinic for diagnosis, along with three samples sent to us by other institutes (accessions HF586387, HF586390, HF586391). In the same period, amplification failed from two samples with an extremely low parasite load. We provide a detailed protocol and sequence reference set on the website www. itg.be/LeishmaniaHSP70, which outlines a step-bystep guideline of the PCRs, sequencing, and interpretation. We acknowledge that implementing sequence analysis in a routine diagnostic laboratory may be difficult in some settings and that the entire analysis may take a few days. Nevertheless, in our hands the method proved highly convenient, and in view of the few samples diagnosed per year, more cost-effective than validating a high-throughput system with a simple readout. Alternatively, sequencing could provide a clear identification in case other assays fail .

The more disputable species designations are $L$. infantum, L. panamensis, and L. peruviana, as all these were moderately bootstrap-supported subgroups of the highly robust $L$. donovani, $L$. guyanensis, and $L$. braziliensis complexes, respectively, as previously documented $[9,19,26-29,31-35]$. In case of doubt, the complex level should be reported rather than the exact species. From a clinical point of view, discriminating $L$. infantum from $L$. donovani is not highly relevant, since both species can cause visceral leishmaniasis and treatment is the same $[26,36]$. Also the discrimination 
between L. guyanensis and L. panamensis is not a priority in clinical practice [36]. Separating L. braziliensis from $L$. peruviana is considered more relevant, because $L$. braziliensis potentially causes mucocutaneous complications, while L. peruviana generally does not [34]. As no markers are currently available that discriminate strains that do from those that do not cause mucocutaneous leishmaniasis, identification at the species level is the only option. Both MLEE and genetic analyses have revealed that $L$. peruviana is a subcluster in the L. braziliensis complex, but discrimination is impaired by the fact that many parasites of this complex seem to have a composite genotype carrying signatures of both species [19,32-35]. The situation is further complicated by the fact that occasionally, $L$. peruviana can cause mucocutaneous disease [34]. Isolates belonging to the L. braziliensis outlier group have been isolated from mucous lesions as well (data not shown), but whether these were primary or secondary infections is not known. Two other tightly linked species in the hsp7o dendrogram are L. tropica and L. aethiopica. Although the $L$. tropica isolates cover the entire endemic region, from Morocco to eastern Africa, the Middle-East, and India, they form a clearly separated recognisable group. The same applies to separating $L$. mexicana from L. amazonensis, even though the latter could not be distinguished from L. garnhami.

One may wonder why some of the above species in the recognised larger complexes seem less clearly defined by sequencing than by single-nucleotide polymorphism (SNP) assays such as species-specific PCRs or RFLP analysis. The reason is that these assays use a point mutation in the genome of the parasite, which is either present or absent, thereby allowing a binary discrimination. When using sequences, much more information is provided from many polymorphisms and is sometimes contradictory. Typing based on sequencing can therefore be more difficult, but it is more reliable as it uses more data. An accidental mutation may lead to erroneous conclusions in a SNP-based assay, while this is less likely when analysing entire sequences.

The current complete set of trustworthy sequences that can be used for typing amounts to 203, representing 15 species of human medical importance, and originating from 41 endemic countries. This reference set is updated continuously for further improvement of the geographic and genetic coverage, to ensure an adequate representation of the existing inter- and intraspecies variability. Some species are over-represented from some regions (such as in Peru), but that does not interfere with the typing outcome. It is of crucial importance to base species typing upon sequences that have been quality-checked. In practice, BLAST searches are often used for identification purposes, on the basis of hsp7o sequences found in public databases such as GenBank. We have found several instances where the species designation reported in these databases was incorrect. For example, in entries JXo21425 up to JX021443 and JX970993 up to JX970996, several erroneous $L$. donovani sequences are reported, even disagreeing with the species assignment as listed in the related publication [23]. Two entries were here shown related to Leptomonas rather than Leishmania (Figure 3 and supplementaty dendrogram). Two entries were determined from the $L$. infantum type strain MHOM/FR/78/LEM75: Yo8020 and X85798. Both sequences clearly grouped with $L$. tropica, unlike all genuine $L$. infantum sequences in our analysis. This illustrates that one should be extremely careful when using sequences that have not been quality-controlled for species typing by comparison with other sequences from the same species, as this could result in incorrect typing outcomes, with potential adverse consequences for the patient.

As with all other assays based on the analysis of a single genomic locus, it is assumed that the relationship between the sequences mirror the relationship between the parasites. A first requirement to meet this objective is to avoid the use of paralogous sequences. This poses no problem in the case of hsp7o because, although this gene is part of a gene family [18], the primers used in our protocol specifically amplify only one of the family members. Another problem is presented by the occasional inter-species hybrids that have been reported $[19,34,37-40]$, and that are not necessarily evidenced in all genes. Nevertheless, such hybrids do not necessarily go undetected when looking at single genomic loci. For instance, isolate MHOM/PE/2006/CU00181, by AFLP clearly identified as a hybrid between L. braziliensis and L. braziliensis outliers [19], also holds an intermediate position in hsp7o sequences (Figure 3 and supplementary dendrogram). On the contrary, MHOM/PE/2003/LH2538, also shown to be a hybrid between these two clusters, grouped with $L$. braziliensis. As this isolate derived a much smaller proportion of its genome from the $L$. braziliensis outliers, such classification is however not problematic. In natural $L$. donovani-L. aethiopica hybrids, both species alleles were present in all genes investigated, including hsp7o [38]. In an L. infantum-L. major hybrid, both genomes were present [39], hence enabling to type the parasite based on a single gene assay. Theoretically, the chance of detecting inter-species recombinants increases as more loci are analysed, such as in multilocus-microsatellite, -sequence and -enzyme electrophoresis assays, but this also raises the cost and time of species typing. Given all currently available evidence on the potential of $h s p 70$ to detect reported inter-species hybrids, and as such hybrids are rare, we consider this a negligible setback of using the $h s p 70$ single-locus assay for routine species typing. Nevertheless, additional more variable genes may be able to perform better in discriminating within the complexes, but this would probably require a separate approach for each complex or subgenus [32,41,42].

Ultimately, the use of single-locus sequencing for species discrimination could be substituted by wholegenome sequencing [43]. With this method becoming 
cheaper, it may soon be the standard in clinical studies. Comparison of whole-genome information could reveal clinically relevant intra-species differences, and has the highest chance of detecting recombination events. Such typing methodology could even make abstraction of the classical concept of typing at the taxonomic levels of species and species complexes [44]. It could open up a whole new era of relating strains on the basis of a selection of genes relevant for disease progression and treatment options, rather than based upon species definitions that may at times not correlate with clinical outcome. Nevertheless, whole-genome sequencing seems at present miles away from being implemented in everyday clinical practice, not only because of the complexity of data analysis, but also because it is complicated by the presence of human DNA contamination in clinical samples and related ethical issues. In the meantime there is a need for standardised methods to identify Leishmania strains. We advocate that hsp7o has this potential: the gene is easily amplified, it can be analysed by sequencing in high-resource settings, and by simpler methods such as RFLP in limitedresource endemic areas $[12,45]$. If a global database of $h s p 70$ sequences from endemic regions were to be established, new sequences found in imported leishmaniasis could immediately be related to documented parasites, with clinical information on the patients from whom they were isolated. Such analysis could even be independent of currently used species boundaries, and provide adequate links based on genetic similarity irrespective of the species.

\section{Conclusion}

We present in this paper a complete validation and globally applicable standardised protocol for the use of hsp7o sequences in Leishmania typing. As this validation includes a detailed comparison with other species identification methods currently used in various laboratories, we feel that implementation of the here presented typing strategy in a clinical diagnostic laboratory should be straight-forward, and could entail the validation of only the sequencing process itself rather than the actual species assignment, in view of this report. We intend to further promote our strategy, to identify additional strains with linked clinical information, and to establish a global database of circulating Leishmania parasites.

\section{Acknowledgements}

The authors would like to thank Ingrid Felger (Swiss Tropical and Public Health Institute, Basel, Switzerland), Aldert Bart (Academic Medical Centre, Amsterdam, The Netherlands), Mark Bailey (Army Medical Directorate, Camberley, UK), and Ricardo Lleonart (INDICASAT, Panama City, Panama) for providing DNA from strains and clinical samples. We acknowledge the constructive input from all colleagues of the LeishMan consortium. We appreciate the help of Eva De Clercq (Université Catholique de Louvain, Louvain-la-Neuve, Belgium) for the construction of Figure 2. Salary support of GVDA was provided by the Belgian Directorate General for Development cooperation (third framework agreement with ITM).
References

1. Bailey MS, Lockwood DN. Cutaneous leishmaniasis. Clin Dermatol. 2007;25(2):203-11

http://dx.doi.org/10.1016/j.clindermatol.2006.05.008 PMid:17350500

2. Bailey MS, Green AD, Ellis CJ, O’Dempsey TJ, Beeching NJ, Lockwood DN, et al. Clinical guidelines for the management of cutaneous leishmaniasis in British military personnel. J R Army Med Corps. 2005;151(2):73-80.

http://dx.doi.org/10.1136/jramc-151-02-03 PMid:16097110

3. Schwartz E, Hatz C, Blum J. New world cutaneous leishmaniasis in travellers. Lancet Infect Dis. 2006;6(6):342-9. http://dx.doi.org/10.1016/S1473-3099(06)70492-3

4. Blum JA, Hatz CF. Treatment of cutaneous leishmaniasis in travelers 2009. J Travel Med. 2009;16(2):123-31. http://dx.doi.org/10.1111/j.1708-8305.2008.00286.x PMid:19335813

5. Mitropoulos P, Konidas P, Durkin-Konidas M. New World cutaneous leishmaniasis: updated review of current and future diagnosis and treatment. J Am Acad Dermatol. 2010;63(2):30922.

http://dx.doi.org/10.1016/j.jaad.2009.06.088 PMid:20303613

6. Goto H, Lindoso JA. Current diagnosis and treatment of cutaneous and mucocutaneous leishmaniasis. Expert Rev Anti Infect Ther. 2010;8(4):419-33.

http://dx.doi.org/10.1586/eri.10.19

PMid:20377337

7. Buffet PA, Rosenthal E, Gangneux JP, Lightburne E, Couppie P, Morizot G, et al. Therapy of leishmaniasis in France: consensus on proposed guidelines. Presse Med. 2011;40(2):173-84 http://dx.doi.org/10.1016/j.lpm.2010.09.023 PMid:21106333

8. Boecken G, Sunderkotter C, Bogdan C, Weitzel T, Fischer $M$, Muller A, et al. Diagnosis and therapy of cutaneous and mucocutaneous leishmaniasis in Germany. J Dtsch Dermato Ges. 2011;9 Suppl 8:1-51.

http://dx.doi.org/10.1111/j.1610-0379.2011.07820.x PMid:22050890

9. Fraga J, Montalvo AM, De Doncker S, Dujardin JC, Van der Auwera G. Phylogeny of Leishmania species based on the heatshock protein 70 gene. Infect Genet Evol. 2010;10(2):238-45. http://dx.doi.org/10.1016/j.meegid.2009.11.007 PMid:19913110

10. Fraga J, Veland N, Montalvo AM, Praet N, Boggild AK, Valencia $B M$, et al. Accurate and rapid species typing from cutaneous and mucocutaneous leishmaniasis lesions of the New World. Diagn Microbiol Infect Dis. 2012;74(2):142-50. http://dx.doi.org/10.1016/j.diagmicrobio.2012.06.010 PMid:22819605

11. Montalvo AM, Fraga J, Monzote L, Montano I, De Doncker S, Dujardin JC, et al. Heat-shock protein 70 PCR-RFLP: a universal simple tool for Leishmania species discrimination in the New and Old World. Parasitology. 2010;137(8):1159-68 http://dx.doi.org/10.1017/So031182010000089 PMid:20441679

12. Montalvo AM, Fraga J, Maes I, Dujardin JC, Van der Auwera G. Three new sensitive and specific heat-shock protein 70 PCRs for global Leishmania species identification. Eur J Clin Microbiol Infect Dis. 2012;31(7):1453-61. http://dx.doi.org/10.1007/s10096-011-1463-z PMid:22083340

13. Garcia L, Kindt A, Bermudez H, Llanos-Cuentas A, De Doncker $S$, Arévalo J, et al. Culture-independent species typing of neotropical Leishmania for clinical validation of a PCR-based assay targeting heat shock protein 70 genes. J Clin Microbiol. 2004;42(5):2294-7.

http://dx.doi.org/10.1128/JCM.42.5.2294-2297.2004 PMid:15131217 PMCid:PMC 404633

14. Marfurt J, Nasereddin A, Niederwieser I, Jaffe CL, Beck HP, Felger I. Identification and differentiation of Leishmania species in clinical samples by PCR amplification of the miniexon sequence and subsequent restriction fragment length polymorphism analysis. J Clin Microbiol. 2003:41(7):3147-53.

http://dx.doi.org/10.1128/JCM.41.7.3147-3153.2003 PMid:12843055 PMCid:PMC165364

15. Schönian G, Nasereddin A, Dinse N, Schweynoch C, Schallig HD, Presber W, et al. PCR diagnosis and characterization of Leishmania in local and imported clinical samples. Diagn Microbiol Infect Dis. 2003;47(1):349-58 http://dx.doi.org/10.1016/S0732-8893(03)00093-2

16. Stevenson LG, Fedorko DP, Zelazny AM. An enhanced method for the identification of Leishmania spp. using real-time polymerase chain reaction and sequence analysis of the $7 \mathrm{SL}$ 
RNA gene region. Diagn Microbiol Infect Dis. 2010;66(4):432-5. http://dx.doi.org/10.1016/j.diagmicrobio.2009.11.005 PMid:20226334 PMCid:PMC2856081

17. Roelfsema JH, Nozari N, Herremans T, Kortbeek LM, Pinelli E. Evaluation and improvement of two PCR targets in molecular typing of clinical samples of Leishmania patients. Exp Parasitol. 2011;127(1):36-41.

http://dx.doi.org/10.1016/j.exppara.2010.06.024 PMid:20599989

18. Folgueira C, Ca-avate C, Chicharro C, Requena JM. Genomic organization and expression of the HSP70 locus in New and Old World Leishmania species. Parasitology. 2007;134(Pt 3):369-77. http://dx.doi.org/10.1017/So031182006001570 PMid:17054823

19. Odiwuor S, Veland N, Maes I, Arévalo J, Dujardin JC, Van der Auwera G. Evolution of the Leishmania braziliensis species complex from amplified fragment length polymorphisms, and clinical implications. Infect Genet Evol, 2012;12(8):1994-2002. http://dx.doi.org/10.1016/j.meegid.2012.03.028 PMid:22516226

20. Deborggraeve S, Laurent T, Espinosa D, Van der Auwera G, Mbuchi M, Wasunna M, et al. A simplified and standardized polymerase chain reaction format for the diagnosis of leishmaniasis. J Infect Dis. 2008;198(10):1565-72. http://dx.doi.org/10.1086/592509 PMid:18816188

21. Odiwuor S, Muia A, Magiri C, Maes I, Kirigi G, Dujardin JC, et al. Identification of Leishmania tropica from micro-foci of cutaneous leishmaniasis in the Kenyan Rift Valley. Pathog Glob Health. 2012;106(3):159-65. http://dx.doi.org/10.1179/2047773212Y.0000000015 PMid:23265373

22. DNA Baser Sequence Assembler. Nucleotide ambiguity code. Pitesti: Heracle BioSoft S.R.L. Available from: http://www. dnabaser.com/articles/IUPAC\%20ambiguity\%2ocodes.html

23. Zhang CY, Lu XJ, Du XQ, Jian J, Shu L, Ma Y. Phylogenetic and evolutionary analysis of Chinese Leishmania isolates based on multilocus sequence typing. PLoS One. 2013;8(4):e63124. http://dx.doi.org/10.1371/journal.pone.0063124 PMid:23646184 PMCid:PMC3639960

24. Tamura K, Peterson D, Peterson N, Stecher G, Nei M, Kumar S. MEGA5: molecular evolutionary genetics analysis using maximum likelihood, evolutionary distance, and maximum parsimony methods. Mol Biol Evol. 2011;28(10):2731-9. http://dx.doi.org/10.1093/molbev/msr121 PMid:21546353 PMCid:PMC3203626

25. Mauricio IL, Stothard JR, Miles MA. The strange case of Leishmania chagasi. Parasitol Today. 2000;16(5):188-9. http://dx.doi.org/10.1016/S0169-4758(00)01637-9

26. Lukeš J, Mauricio IL, Schönian G, Dujardin IC, Soteriadou K, Dedet JP, et al. Evolutionary and geographical history of the Leishmania donovani complex with a revision of current taxonomy. Proc Natl Acad Sci USA. 2007;104(22):9375-80. http://dx.doi.org/10.1073/pnas.0703678104 PMid:17517634 PMCid:PMC1890502

27. Ba-uls AL, Hide M, Tibayrenc M. Evolutionary genetics and molecular diagnosis of Leishmania species. Trans R Soc Trop Med Hyg. 2002;96 Suppl 1:S9-13. http://dx.doi.org/10.1016/So035-9203(02)90045-3

28. Bañuls $A L$, Jonquieres $R$, Guerrini $F$, Le Pont $F$, Barrera $C$, Espinel I, et al. Genetic analysis of Leishmania parasites in Ecuador: are Leishmania (Viannia) panamensis and Leishmania (V.) guyanensis distinct taxa? Am J Trop Med Hyg. 1999;61(5):838-45.

29. Cupolillo E, Grimaldi G Jr, Momen H. A general classification of New World Leishmania using numerical zymotaxonomy. Am J Trop Med Hyg. 1994;50(3):296-311.

PMid:8147488

30. Srivastava P, Prajapati VK, Vanaerschot M, Van der Auwera G, Dujardin IC, Sundar S. Detection of Leptomonas sp. parasites in clinical isolates of Kala-azar patients from India. Infect Genet Evol. 2010;10(7):1145-50. http://dx.doi.org/10.1016/j.meegid.2010.07.009 PMid:20633704 PMCid:PMC2933273

31. Odiwuor S, Vuylsteke M, De Doncker S, Maes I, Mbuchi M, Dujardin JC, et al. Leishmania AFLP: paving the way towards improved molecular assays and markers of diversity. Infect Genet Evol. 2011;11(5):960-7. http://dx.doi.org/10.1016/j.meegid.2011.03.008 PMid:21439405

32. Oddone R, Schweynoch C, Schönian G, de Sousa CS, Cupolillo E, Espinosa D, et al. Development of a multilocus microsatellite typing approach for discriminating strains of Leishmania (Viannia) species. J Clin Microbiol. 2009;47(9):2818-25.
http://dx.doi.org/10.1128/JCM.00645-09

PMid:19587302 PMCid:PMC2738093

33. Veland N, Boggild AK, Valencia C, Valencia BM, LlanosCuentas A, Van der Auwera G, et al. Leishmania (Viannia) species identification on clinical samples from cutaneous leishmaniasis patients in Peru: assessment of a molecular stepwise approach. J Clin Microbiol. 2012;50(2):495-8. http://dx.doi.org/10.1128/JCM.05061-11

PMid:22116151 PMCid:PMC3264178

34. Nolder D, Roncal N, Davies CR, Llanos-Cuentas A, Miles MA. Multiple hybrid genotypes of Leishmania (Viannia) in a focus of mucocutaneous leishmaniasis. Am J Trop Med Hyg. 2007;76(3):573-8 PMid:17360886

35. Bañuls AL, Dujardin JC, Guerrini F, De Doncker S, Jacquet D, Arevalo J, et al. Is Leishmania (Viannia) peruviana a distinct species? A MLEE/RAPD evolutionary genetics answer. J Eukaryot Microbiol. 2000;47(3):197-207. http://dx.doi.org/10.1111/j.1550-7408.2000.tbo0039.x

36. World Health Organization (WHO). Control of the leishmaniasis: report of a meeting of the WHO Expert Committee on the Control of Leishmaniases, Geneva, 22-26 March 2010. Geneva, Switzerland: WHO; 2010. Available from: http://whqlibdoc. who.int/trs/WHO_TRS_949_eng.pdf

37. Belli AA, Miles MA, Kelly JM. A putative Leishmania panamensis/Leishmania braziliensis hybrid is a causative agent of human cutaneous leishmaniasis in Nicaragua. Parasitology. 1994;109(Pt 4):435-42. http://dx.doi.org/10.1017/S0031182000080689 PMid:7800411

38. Odiwuor S, De Doncker S, Maes I, Dujardin JC, Van der Auwera G. Natural Leishmania donovani/Leishmania aethiopica hybrids identified from Ethiopia. Infect Genet Evol. 2011;11(8):2113-8. http://dx.doi.org/10.1016/j.meegid.2011.04.026 PMid:21558020

39. Ravel C, Cortes S, Pratlong F, Morio F, Dedet JP, Campino L. First report of genetic hybrids between two very divergent Leishmania species: Leishmania infantum and Leishmania major. Int J Parasitol. 2006;36(13):1383-8. http://dx.doi.org/10.1016/j.ijpara.2006.06.019 PMid:16930606

40. Delgado O, Cupolillo E, Bonfante-Garrido R, Silva S, Belfort E, Grimaldi JG, et al. Cutaneous leishmaniasis in Venezuela caused by infection with a new hybrid between Leishmania (Viannia) braziliensis and L. (V.) guyanensis. Mem Inst Oswaldo Cruz. 1997;92(5):581-2. http://dx.doi.org/10.1590/So074-02761997000500002 PMid:9566221

41. Kuhls K, Keilonat L, Ochsenreither S, Schaar M, Schweynoch C, Presber W, et al. Multilocus microsatellite typing (MLMT) reveals genetically isolated populations between and within the main endemic regions of visceral leishmaniasis. Microbes Infect. 2007;9(3):334-43. http://dx.doi.org/10.1016/j.micinf.2006.12.009 PMid:17307010

42. Zemanová E, Jirku M, Mauricio IL, Horák A, Miles MA, Lukeš J. The Leishmania donovani complex: genotypes of five metabolic enzymes (ICD, ME, MPI, G6PDH, and FH), new targets for multilocus sequence typing. Int J Parasitol. 2007;37(2):149-60. http://dx.doi.org/10.1016/j.ijpara.2006.08.008 PMid:17027989

43. Downing T, Imamura H, Decuypere S, Clark TG, Coombs $\mathrm{GH}$, Cotton JA, et al. Whole genome sequencing of multiple Leishmania donovani clinical isolates provides insights into population structure and mechanisms of drug resistance. Genome Res. 2011;21(12):2143-56. http://dx.doi.org/10.1101/gr.123430.111 PMid:22038251 PMCid:PMC3227103

44. Van der Auwera G, Fraga J, Montalvo AM, Dujardin JC. Leishmania taxonomy up for promotion? Trends Parasitol. 2011;27(2):49-50. http://dx.doi.org/10.1016/j.pt.2010.11.007 PMid:21147036

45. da Silva LA, dos Santos de Sousa C, da Graça GC, Porrozzi $R$, Cupolillo E. Sequence analysis and PCR-RFLP profiling of the hsp70 gene as a valuable tool for identifying Leishmania species associated with human leishmaniasis in Brazil. Infect Genet Evol. 2010;10(1):77-83 http://dx.doi.org/10.1016/j.meegid.2009.11.001 PMid:19913112

46. Alvar J, Velez ID, Bern C, Herrero M, Desjeux P, Cano J, et al. Leishmaniasis Worldwide and Global Estimates of Its Incidence. PLoS One. 2012;7(5):e35671. http://dx.doi.org/10.1371/journal.pone.0035671 PMid:22693548 PMCid:PMC3365071 